\title{
The social dynamics in establishing complex community climate change initiatives: the case of a community fridge in Scotland
}

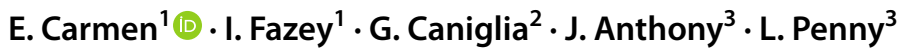

Received: 4 March 2021 / Accepted: 15 November 2021 / Published online: 18 December 2021

(c) The Author(s) 2021

\begin{abstract}
Multiple factors are involved in community change processes, yet understanding how factors interact to shape these complex social processed is limited. This has important implications for both research and sustainability practice. This study examines key social dynamics in establishing complex community change initiatives using an in-depth action-oriented transdisciplinary approach with a case study of the development of a community fridge. Four critical social dynamics were identified: reinforcing interpretations, reinforcing interconnections, re-alignment of identities, and quality social relations involving multiple normative facets converging and diverging in different ways as the process unfolded. Initially, this led to a degenerative dynamic that heightened tensions between actors; however, re-alignment with wider social identities and expressions of the underlying normative dimensions involved in the initiative, a regenerative dynamic was created. This strengthened the conditions to support shared understanding, learning and enhanced relationships to enable different actors to work together to shape aspects of the initiative. Overall, the study highlights that future community-based change initiatives need to be guided by explicit approaches that work with social relationships, but where these relationships are conceptualised as dynamic normative spaces of interaction and exploration. This can inform understanding on how to develop beneficial reinforcing regenerative dynamics, where advances in one aspect of social relationships within initiatives can begin to reinforce others and ways that increase collective capacity as a whole. Developing this regenerative potential through social relationships within initiatives is thus critical for engaging with complex challenges across communities.
\end{abstract}

Keywords Social dynamics $\cdot$ Social relationships $\cdot$ Social capital $\cdot$ Meaning-making $\cdot$ Regenerative $\cdot$ Community initiatives

\section{Introduction}

Overcoming and working with challenges like climate change and food insecurity require deliberate change across societies to guide more sustainable futures (Vermeulen et al. 2012; Bohle et al. 1994). Such challenges are dynamically complex, with issues interconnected and continuously configured over time and across spatial scales (Preiser et al.

Handled by Graham Epstein, University of Waterloo Faculty of Environment, Canada.

E. Carmen

esther.carmen78@yahoo.co.uk

1 Department of Environment and Geography, University of York, Heslington, York, UK

2 Konrad Lorenz Institute for Evolution and Cognition Research, Klosterneuburg, Austria

3 Gate Church Carbon Saving Project, Dundee, UK
2018). Collective change processes within these contexts are non-linear, with complex patterns emerging as different actors try to make sense of challenges and engage in different ways (Stedman 2016; Andrachuk and Armitage 2015; Schlüter et al. 2019). Broad social engagement is necessary to work with such issues, but change efforts are also challenging, as actors with diverse perspectives and preferences come together and with the need to develop shared concerns and problem-solving capacities (Etzion et al. 2017; Voss et al. 2007). Developing understanding of how social actors work with and through such complexity, including the diverse values and perspectives involved, is thus critical to advancing knowledge about how to strengthen community sustainability initiatives within the wider context of rapid global social and environmental change.

Across the world, different groups of community-based actors are engaging with complex challenges. Understanding the social dynamics that shape how these processes develop is important, yet many questions still remain about how 
different facets interact to shape these processes (Mancilla García et al. 2020; Köhler et al. 2019; Igalla et al. 2019) and how more effective practices can be supported (Fazey et al. 2018b). Structural approaches are often considered key, such as those focusing on enhancing governance to support change (e.g. Laakso et al. (2017), Becker et al. (2018)). This, however, often leads to a focus on developing more formalised decision-making processes and on the role of strategic actors in change (Strambach and Pflitsch 2018). There is now growing recognition that enabling approaches, which harness human agency and capacities through softer and less tangible aspects including navigating normative and emotional aspects, are important for shaping change (Scoones et al. 2020). Enhancing understanding of these aspects is essential for providing more nuanced 'human felt' understandings and for attending to the 'real and lived experiences' associated with change, which affect how change initiatives unfold (Fazey et al. 2021).

This study therefore aims to examine the human social and cultural dynamics in community-level initiatives within a wider context of social and environmental sustainability to inform how such initiatives can be improved in practice. The work is based on an in-depth investigation of an initiative to establish a community fridge in an urban context in Scotland that aimed to meet multiple interconnected goals, including helping reduce food waste, mitigate climate change and supporting provision of food to those in need. First, we provide an overview of what is currently known about some of the social dynamics of community change and sustainability initiatives. We then outline the transdisciplinary methodology and case study, followed by presentation of the findings relating to the key social dynamics that were important in shaping the development of the initiative. Finally, we discuss implications for understanding and guiding complex change processes. The paper is novel in the way it seeks to draw out lessons for practice from understanding the deeper social-cultural dimensions associated with change. It will thus have wide relevance to those seeking to advance knowledge about sustainability and change in practice.

\section{Conceptual background}

Community-based change initiatives are purposeful, selforganised interventions by community-based actors who mobilise energy and resources with the aim of creating collective change (Igalla et al. 2019). These are complex social processes that are influenced by multiple factors that coalesce and shift over time (Boulton et al. 2015; Fazey et al. 2016), particularly as they engage with different aspects of community life, such as livelihoods and natural environment and values, discourses and practices (Pelling et al. 2015). As these aspects interact, tensions and conflict emerge as different understandings of problems and possible solutions surface (Hahn and Nykvist 2017; Fazey et al. 2021). Sustainability initiatives thus tend to be dynamic and multifaceted (Fazey et al. 2021). This then requires approaches that help: (1) stimulate continual learning (Fazey et al. 2018a), (2) enhance social relationships between actors (Carmen et al. 2022) and (3) work with diverse emotive and other normative dimensions (Grenni et al. 2020). Each of these three aspects is expanded on below.

First, enhancing opportunities for collective learning is critical in community-based initiatives to draw out and work with different perspectives, experiences and expertise (Fazey et al. 2021; Caniglia et al. 2020). Learning is a cognitive process through which new insights and 'ways of seeing' phenomena develop (McFarlane 2011; Reed et al. 2010). This can be understood as different types of learning, ranging from the most basic level with improvement in existing habits, to conscious reflection about individual choices and assumptions leading to new habits that shape future preferences and actions, for example in relation to accessing and using food (Garnett 2014), or more fundamentally in shaping how actors see and position themselves in the world (Fahrenbach and Kragulj 2019). Whilst learning unfolds through experience, this can be enhanced by critical reflection that may shift how problems, possible constraints, opportunities and consequences of actions are understood (Pelenc et al. 2015; Ansell 2011). Deeper learning is therefore recognised as a critical dimension for creating meaningful opportunities for transformative change (MacIntyre et al. 2018). Shaping and embracing opportunities for learning is thus important in practice, but it is less clear how this can be effectively achieved among a dynamically interacting set of issues across regions and scales to help align values, perspectives and actors on the ground so as to bring about meaningful change.

Second, building social relationships that connect actors is widely recognised as important for shaping change (Rockenbauch and Sakdapolrak 2017; Emery and Bregendahl 2014). Social relationships and networks are often framed as social capital, which views these aspects as a resource to help shape different outcomes with varying desirability for different actors depending on the nature of the relationships (Dale and Onyx 2010). Whilst social capital is a contested concept, different facets of social capital are widely recognised (Phillips 2016), including different connections between individual actors (Bodin and Crona 2009); the nature of interactions, such as trust and social norms (MacGillivray 2018); and outcomes arising from them, such as ideas and learning, improved health or enhanced collective action (Hausman et al. 2005; Kilpatrick and Falk 2003). Most studies of change initiatives, however, place an emphasis on analysing the different actors involved (e.g. Laycock and Mitchell 2019), the 
networks and connections (e.g. Moore and Westley 2011) and on the importance of trust (e.g. Chow and Chan 2008) and often with focus on large-scale social networks (de Vos et al. 2019). Social relationships are a core dimension of the concept of social capital and of social networks. There has, however, been much less attention on how different dimensions of social capital and networks come together and interact over time, leading to critiques of simplistic approaches and a lack of engagement with the dynamics involved (Carmen et al. 2022; Rockenbauch et al. 2019; Rockenbauch and Sakdapolrak 2017; Samouel 2007).

Social relationships develop through ongoing dyadic interactions and co-constructed understandings between individuals (Eberly et al. 2011). This includes co-constructed meanings about the interactions themselves, including the actors involved, their perspectives, interests and expectations (Bernhard 2018). This co-construction then provides opportunities to shape how problems, solutions, or future consequences and goals are defined (Madsen and O'Mullan 2016). Further research is therefore needed that helps develop more nuanced understandings of the role of the social relationships in collective change processes and how to work with social relationships to shape how change unfolds. This study therefore inductively examines social relationships within the dynamics of complex change processes.

Finally, it has been long understood that working with the complexity of sustainability challenges requires attending to diverse normative dimensions. This includes social identities, emotions, values and norms within sustainability initiatives (Ryan 2016; Voss et al. 2007). Social identities are multifaceted, including how groups want to be viewed in relation to particular contexts (Fresque-Baxter and Armitage 2012), within particular places or with/by different social groups (Grenni et al. 2020). Values relate to what is considered important (Horlings 2015), often expressed as preferences, whereas social norms can be understood as collective expectations of behaviour (Fehr and Fischbacher 2004). Such normative dimensions are important for guiding what is or is not considered acceptable, including in relation to the actions of others (Gorddard et al. 2016; Smith et al. 2012). Multiple normative dimensions across temporal and spatial scales are therefore involved in shaping perceptions of what is and is not possible (Everard et al. 2016), how problems are defined, acceptability of possible solutions, and how actors interact (Granderson 2014). This dynamic interplay of such factors often leads to surfacing of contradictions and tensions between actors (Demski et al. 2015). Whilst working with normative dimensions may not on their own be sufficient for change (Katrini, 2018), they are increasingly recognised as important in shaping the kinds of change which emerge (O'Brien and Sygna 2013). Many studies and most change initiatives fail to take such dimensions into account, underestimating their importance. Understanding such aspects and their interplay with other factors is thus critical for enhancing capacities to support sustainability.

Overall, while there is a growing number of studies on social factors in relation to sustainability initiatives, many have focused on more formalised processes and structural or 'harder' dimensions involved, and much less on the way diverse, multiple social and cultural factors interact over time. They have also rarely attended to understanding the interaction between the different aspects highlighted above and the overall social dynamics that occur when a more holistic perspective of these issues are considered. Advancing such understanding is critical for providing insights about how actors come together, understand, and act and for providing insights about how community-level change can be more effectively stewarded.

\section{Methodology and methods}

\section{Research approach}

The work was informed by a complexity ontology. This views the nature of reality as emerging through non-linear interactions between different elements which interconnect in multiple ways over temporal and spatial scales to form dynamic and potentially recursive processes that shape human experience (Byrne and Callaghan 2014). An inductive research approach was applied, which involves being open to diverse interpretations within the data, examining patterns to establish new generalised insights that can be constrained by adopting specific theoretical lens to structure data collection and analysis (Blaikie 2010). Social dynamics are therefore understood as encompassing diverse aspects (of communities and initiatives) and thus a broad set of concepts and terms. In the case of this paper, we sought to draw out a diversity of interacting social dynamics (e.g. those outlined above) rather than being initially constrained by focusing on one particular framing of them (e.g. social capital).

A transdisciplinary approach was used to explore social dynamics based on an in-depth qualitative case study. Transdisciplinary research aims to address real-world problems alongside a commitment to develop new, relevant insights to the problem in question (Lang et al. 2012) by working through more equal relationships between scientific and social actors as knowledge is co-created (van Kerkhoff 2014). In practice, this involves a rejection of assumptions that knowledge comes from a researcher being independent to what they observe, and instead recognising the value of researchers being able learn by doing and by being much more deeply involved with the actors seeking to bring about change (Fazey et al. 2018c). In these approaches, validity arises because a researcher is embedded not by standing 
from the outside looking in, divorced from sense-making as experience unfolds. Rigour is, however, enhanced by continuously reflecting on how a researcher's involvement affects interpretations, with the researcher regularly stepping in and out of the context when a more critical stance is required (Fazey et al. 2018c).

This transdisciplinary study involved a small collaborative team with a background in research (E. Carmen) and from practice (two community-based practitioners). The researcher had multiple roles, including being a: knowledge broker, reflexive social scientist, and transdisciplinary champion that helped the wider team draw out insights that then guided their actions, as well as being a critical friend to help them drive forward the collective efforts in the community-based initiative this study sought to understand (Miah et al. 2015). Thus, while the researcher was not involved in 'doing', they were involved in helping facilitate the core actors' endeavours, in part by collecting information from different actors that enhanced sense-making about what was happening and why.

\section{Case study}

\section{Background}

The case study involved a climate change initiative that aimed to create a new community fridge in an urban context in the City of Dundee (Scotland), with a post-industrial history and population of around 150,000 people. During the twentieth century, Dundee had some of the worst slum conditions in Scotland. This was then followed by extensive economic regeneration and cultural development (Watson 2017). Areas of high social deprivation continue to persist within the city (Scottish Government 2020), but this also sits alongside a strong sense of community, working together, and helping others overcome challenges. Across the city, a network of community-based initiatives has emerged, with a particularly strong focus on responding to social needs and supporting specific social groups. This includes a small team that has been developing various initiatives across the city connecting action for both poverty and the environment.

One such initiative aimed to develop a community fridge. A community fridge is a physical space created for sharing excess food by making it available for use in the community for free. Part of a wider urban food sharing movement (Spring and Biddulph 2020), such initiatives can contribute to climate mitigation by reducing food waste and associated greenhouse gas emissions. Sharing and using excess food may, over time, also help different, more sustainable food practices to develop and involve the potential to support other local needs and aspirations (Morrow 2019). By 2018, over 30 urban community fridges had been established in various guises in England. Yet few, if any, were found in

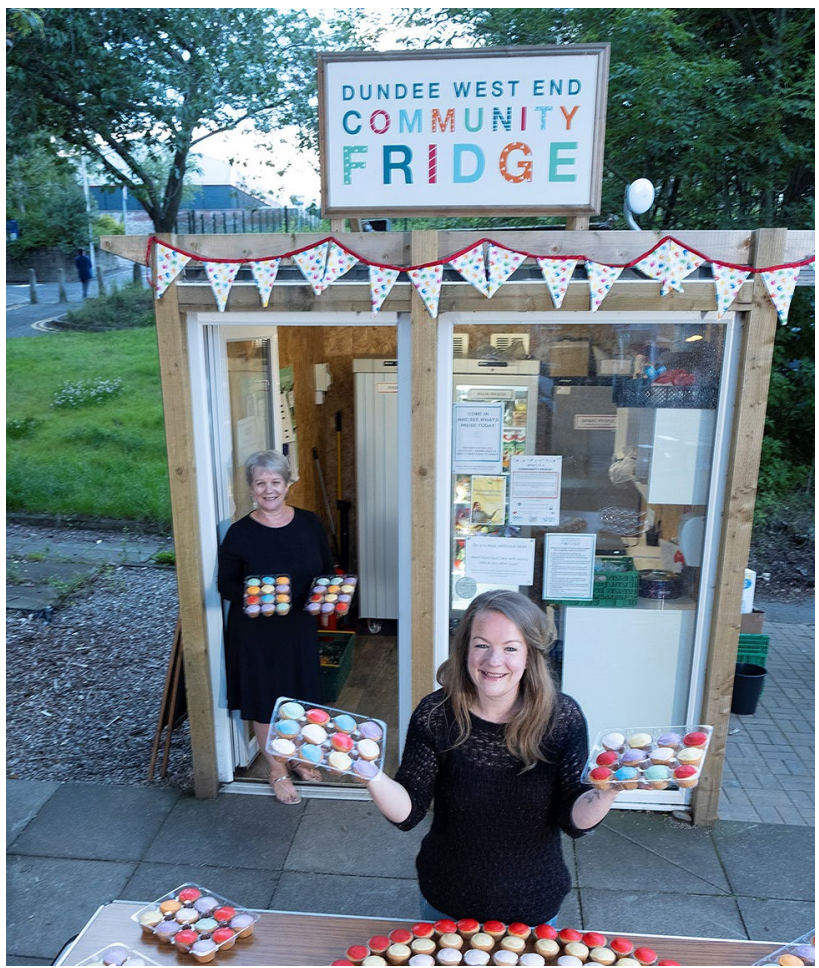

Fig. 1 The exterior view of the new community fridge once established (with a glass front) with interior space where people select surplus food. Image courtesy: Paul Reid (www.anguspictures.com)

Scotland. The small team began to develop a community fridge in 2018 by drawing on learning from other community fridge initiatives elsewhere and other, more local, community initiatives. Core to the design of this initiative was a need to make it accessible to those who needed it. This led to the fridge being established in a small public space, near to the host organisation on the edges of, but still close to, the city centre in an area that included a diversity of independent shops and cafes (Fig. 1).

\section{How the community fridge initiative unfolded}

The aim of this research was not to evaluate the success of the initiative, but rather to understand the social dynamics of the change that occurred. Understanding these dynamics does, however, require an overview of how the initiative unfolded. Once government funding was secured for the initiative, formal planning permission was then sought. As decisions were made about different features of the new space, information was shared with owners of a small business located adjacent to the proposed site. Relatively quickly interactions with these business owners turned negative. A public meeting to understand local concerns was then held. At the same time, local newspaper articles appeared quoting local businesses as describing the area as 'exclusive' and 
that they considered people coming to use the excess food as 'undesirables'. The backlash that arose from this coverage led to some businesses withdrawing their opposition. Some concerns remained and other sites were explored by the project leads and evidence collected to understand impacts on businesses from other fridge initiatives. Given the lack of appropriate alternatives, efforts continued to establish the fridge on the original site. During further meetings with the local businesses, which took an empathic approach, dialogue led to emerging agreements between different parties, including how they could work together to alter external aspects of the fridge, to convey support from businesses and ideas for working together to improve the area in the future. Planning permission was then granted with no objections.

Once established, in the first 6 months (May 2019-Dec 2019) at least 1987 people used the fridge, including some local business owners, and 19.4 tonnes of surplus food was redistributed. The initiative was widely lauded as successful for the local area and the city as a whole by many local actors, including business owners, leading many to suggest developing similar initiatives in other districts. Concerns about potential spill over of the 'them' versus 'us' feelings from the establishment process did arise but were quickly overcome by bringing into play the learning that placed an emphasis on informal face to face dialogue. Overall, the case has provided important insights about how the contested initiative unfolded and the complex social, emotional and cultural issues involved, and the insights this provides for future community-based initiatives.

\section{Methods and materials}

To understand the social dynamics, an iterative and collaborative process of multiple data collection and analysis

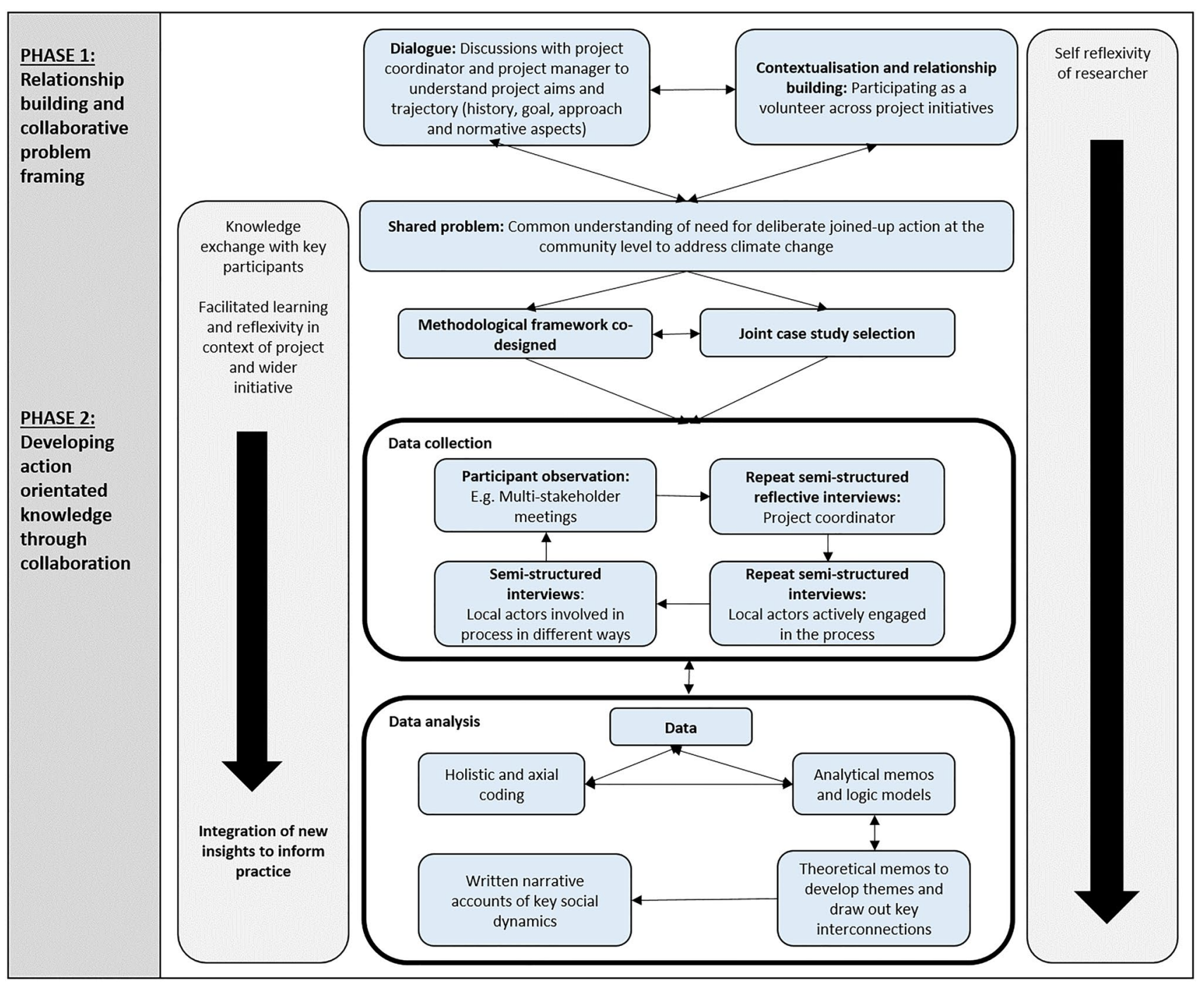

Fig. 2 Transdisciplinary research process 
methods was used. The activities involved can be understood in terms of two distinct phases (Fig. 2).

Phase 1: relationship building and collaborative problem framing. This involved working as a volunteer and regular dialogue to build a shared understanding of values, the broad problem and solution framings across project initiatives, loosely defined around the need for social change at the community level to respond to climate change (Fig. 2).

Phase 2: developing solutions-orientated knowledge through collaboration. This was an iterative phase of the process involving data collection and analysis (Fig. 2). Data were collected through participant observation and semistructured interviewing. Participant observation (180 hours over 10 months) entailed increasingly focused field notes (Gomm 2008; Silverman 2006) with descriptive layers that related to (1) the setting/ wider community; (2) the broader initiative and organisational setting; (3) social and physical dimensions of interactions within specific spaces; (4) researchers' role and interactions in specific spaces; (5) reflections on the process; and (6) self-reflections on values and actions on the process (Crang and Cook 2007). This was supplemented by local news articles and online public responses to these articles. $23 \mathrm{semi}$-structured interviews were also conducted with 15 different key actors for more detailed exploration of specific phenomenon, interconnections and events from the perspectives of key actors engaging in the process (Table 1). Interview guides were developed and probing techniques used to test assumptions and ideas emerging in field observations, increasing richness of the data (Rubin and Ruben 2005). Interviewees were selected based on engagement in deliberations about the initiative. A reflective practice interview design was used with the project coordinator to enhance opportunities for learning and exchange.

Data analysis involved a combination of coding, process modelling and analytical memos. Verbatim interview transcripts and field notes were organised using NVIVO software, annotated and coded holistically to identify key events and broad aspects in the process. As described by Saldana (2016), axial coding techniques were used alongside analytical memos to develop analytical categories to identify factors and conceptual ideas within the data, e.g. social relationships, emotions and learning. The development of logic models can help explore interconnections between factors within complex processes (Quinn Patton 2002) and a series of five logical models were developed alongside theoretical memos to help move from descriptive to more abstract understandings of how the process unfolded. The principle of anti-dualism rejects views of competing claims between concepts, instead being open to seeing these as mutually constituted (Ison 2018; Farjoun et al. 2015). This principle was core throughout the analysis, e.g. in developing analytical categories and to explore interconnections, helping to be open to alternative interpretations within the data as the analysis moved from descriptive to more theoretical accounts. Overall, the research was iterative and collaborative and this greatly enhanced opportunities for exchange and learning, and enabled action-orientated insights to be fed back into the

Table 1 Number of interviews and interviewees

\begin{tabular}{lllll}
\hline Interviewee code & $\begin{array}{l}\text { Level of engage- } \\
\text { ment in process }\end{array}$ & Interview style & Interest/ stake in process & N formal interviews \\
\hline 1.1P & 1 (High) & Reflective practice & Project coordinator (P) & 6 \\
1.2P & 1 (High) & Semi-structured/ narrative & Project manager (P) & 2 \\
1.3B & 1 (High) & Semi-structured/ narrative & Business co-owner (adjacent) (B) & 2 \\
1.4B & 1 (High) & Semi-structured/ narrative & Business co-owner (adjacent) (B) & 1 \\
2.1B & 2 (Medium) & Semi-structured/ narrative & Business owner (nearby) (B) & 2 \\
2.2B & 2 (Medium) & Semi-structured/ narrative & Business owner (nearby) (B) & 1 \\
2.3F & 2 (Medium) & Semi-structured/ narrative & Formal role as local council officer (F) & 1 \\
2.4F & 2 (Medium) & Semi-structured/ narrative & Formal role as local council officer (F) & 1 \\
3.1F & 3 (Low) & Email & Formal role as local council officer (F) & 1 \\
3.2B & 3 (Low) & Semi-structured/ narrative & Business owner (nearby) (B) & 1 \\
3.3B & 3 (Low) & Semi-structured/ narrative & Business owner (nearby) (B) & 1 \\
3.4B & 3 (Low) & Semi-structured/ narrative & Business owner (nearby) (B) & 1 \\
3.5B & 3 (Low) & Semi-structured/ narrative & Business owner (nearby) (B) & 1 \\
3.6B & 3 (Low) & Semi-structured/ narrative & Business owner (nearby) (B) & 1 \\
3.7B & 3 (Low) & Semi-structured/ narrative & Business owner (nearby) (B) & 1 \\
Total interviewees: 15 & & & &
\end{tabular}

For level of engagement: high=engaged throughout; medium = engaged in some aspects; low = no formal engagement in process 
ongoing actions of practitioners within this and other initiatives across the city.

\section{Results}

\section{Social dynamic 1: reinforcing interpretation}

Four core social dynamics unfolded during the establishment process for the community fridge, with each including a range of interconnected factors. The first core social dynamic involved a pattern of reinforcing interpretation, which led to increasing divergent and polarised perspectives and more generally towards a pattern of degenerative social relationships between those in favour and those against the initiative. This process involved an interplay between: concepts applied or understood; assumptions; and emotional responses of the different actors involved. Initially, ideas for establishing the fridge were shared informally with business owners close to the proposed location for the fridge. Here, initiative leads used the concept of a food bank to help explain the initiative. This set a train of interpretive events that included invoking other concepts, such as the notion of providing "food for all" (1.1P), which was new and challenging for some of the business owners. This led to formation of certain assumptions "right at the start" (2.1B) about the initiative being the same as a "foodbank" (1.1P) or "soup-kitchen" (3.2B). This then shaped assumptions about who would use the fridge and why, such as those "who were needy rather than [the fridge being] a community resource" (3.2B). Some struggled to understand why "going and taking something you're not needing because you can afford to buy it" was "being community minded" (3.3B).

As some of the local business owners discussed the fridge, assumptions then became "ingrained" (1.1P), leading to the surfacing of other concepts, such as potential users being "junkies" (1.1P) and "undesirables" (2.4F). These concepts and assumptions, which conveyed unease about the initiative and its potential impact on businesses, were then closely related to the emotions that emerged. One key actor, for example, commented "[very quickly] I started to feel concerned" (1.3B), with the growing sense of fear sometimes manifesting as "aggressive" (2.1B) behaviour. As the project leads became aware of the negative views they organised a formal meeting which, as described by one of the business owners, "got a wee bit out of hand" (1.4B). Business owners felt they "weren't being listened to" (1.3B) while the initiative leads were frustrated about the way they felt business owners viewed them as having just "thought this idea up and not really thought seriously about any of the consequences for businesses" (1.1P). There were also others who held positive views and were excited by the prospect of a local community fridge.

The interplay between concepts, assumptions and emotions, which reinforced positive or negative perspectives, also influenced how the actions of others were interpreted. Some actors interpreted the "level of negativity" (2.4F) expressed by some local actors as "narrow minded" (2.1B) with "an agenda fixed in their head" (2.4F) limiting consideration of "any positive stuff" (1.1P). These assumptions and negative interpretations not only surprised and "confused" (1.1P) the initiative leads, but also invoked further emotional responses, with one interviewee commenting "[I resent their assumption that] poverty equals anti-social behaviour" (2.4F). On the other hand, as information about different perspectives of other actors arose, the initiative leads began to reflect on what was happening and respond, including trying to better understand and inform local business owners. After such an attempt, one business owner commented "[at first] I was affronted as a business.... [but] I felt quite positive after the conversation [with the project coordinator]" (3.2B), and another that "initially it was panic..... [then I became] much more relaxed about it" (2.1B).

Overall, the project was initially beset by a diverging interpretive dynamic, with misunderstanding of the initial concept, which was fed by a reinforcing cycle of negative responses as assumptions were made and emotions came to the fore. Initially, this created divergence and tension, limiting possibilities for some actors to understand how the initiative could work in reality. This social dynamic was thus a process of sense-making and interpretation, which then shaped actions and how actions of others were viewed. While the initiative leads were initially confused because they had not anticipated negative responses, they then started to adapt and shift their approach. While not explicit, this included attempts to break the cycle of negativity by trying to better understand the business owners concerns and better inform them about what was intended.

\section{Social dynamic 2: reinforcing interconnections}

The divergence of, and increasingly polarised perspectives about, the initiative was further enhanced by the second core dynamic of reinforcing interconnections. This involved the influence of social connections, common local identity, and following norms of solidarity. First, existing social connections provided pre-established spaces for interaction and deliberation. This meant that different groups became increasingly convinced about their own interpretations as to what was happening. For example, deliberations between businesses and with customers tended to be with those they already had connections with and often reinforced negative views. 
This was also reinforced by common local identities. For example, a shared sense between small business owners that "priorities every day [were] to make a living... [and we're] a bit protectionist" (3.2B) and that they faced "a bigger risk" (1.3B) than other livelihoods. This collective identity framed deliberations around the potential impacts to small businesses. It also often linked to perceptions of the local areas as being "unique" (1.3B), "exclusive" (2.4F) and "the nice end of town" (3.4B) with many questioning "whether this is the right place [in the city for a fridge]..... because I don't really see that many people needing to use it" (3.3B) and "[it's] a storage container and totally out of context in the area" (1.4B). Identities were further reinforced through mobilisation of a "loose group" (1.4B) of local business owners who were particularly vocal and who highlighted "we're all of the same opinion" (1.3B) and with "[most people] against it" (1.4B). Similarly, initiative leads tended to speak to people they had connections with and who were already more positive, reinforcing positive perspectives, with one lead commenting "everyone I spoke to was just so enthusiastic" (1.1P).

In some cases, deliberation between people led to some assumptions being challenged. More often than not, however, it also led to others coming on board as they conformed to norms of solidarity. For example, motivations for some to participate in the formal meeting came from " $a$ strange sense of loyalty" with a sense that "we should stick together" (2.1B) and "support the others" (2.2B). The combination of connections, identities and norms of solidarity then led to "a group mentality" (1.1P), creating a 'them' and ' $u$ ' framing with one commenting: "I felt there was an atmosphere when I walked in [to the meeting]..... battle lines were drawn" (2.1B). This framing continued to shape discussions within the meeting with, for example, one key actor having commented "why is saving food more important than small businesses and livelihoods?" (1.3B). As these discussions unfolded some participants began to question the arguments against the initiative and their role in this, with one highlighting "there was even mention of a toilet....I thought to myself they don't need a toilet.... [then] I'm starting to think, I'm making things up here just to have something against it" (2.1B).

In summary, the reinforcing interconnection dynamic of existing social connections, shared identities and tendencies to follow norms of solidarity enhanced the first reinforcing interpretation dynamic. This created considerable resistance from local businesses and was difficult for the initiative leads to navigate, especially given that they were also caught up in the same dynamic, albeit leading to a reinforcement of their own positive perspectives of the value of the initiative.
Social dynamic 3: re-alignment with wider identities

The third core social dynamic occurred when wider perspectives beyond the locality influenced the initiative and where a major readjustment occurred when some expression of common local identities were found to be at odds with wider city identities which some recognised as embedded within the initiative design. Around the time of the formal meeting, an unknown local actor highlighted the growing opposition to the initiative to local journalists who began writing articles about this, quoting one business owners use of the concept of "undesirables" and description of the area as "exclusive". The response to this from people across the city was overwhelmingly critical of these notions, which more widely were perceived to not being aligned to the strong city identity about helping others and supporting people. One initiative lead emphasised this disconnect highlighting the "spirit...... [across the city where] people like to help other people" and how business owners wanted "it to be an exclusive area but that doesn't [need to] involve shutting people out" (1.1P). The critical reaction of some city-wide actors led to a sense of vulnerability for some local businesses who felt fear for the future, a sense of "powerlessness ....[from] feeling backed into a corner (1.3B), and being misunderstood. The consequence was that business owners concluded they were unable to continue to openly oppose the initiative, removing all barriers to formal planning approval.

\section{Social dynamic 4: reinforcing quality of social relations}

While it would have been possible to move forward with the development of the fridge irrespective of the feelings of local business owners, the response of initiative leads in their interactions with business owners initiated a more regenerative dynamic, where beneficial outcomes, including collective working and learning, began to emerge. This started from initiative leads showing empathy, which was initially expressed in a meeting with the adjacent business to explain the decision to continue to develop the fridge on the proposed site.

The meeting led to sharing perspectives and exploring alternative ideas and through this process a shared understanding began to take shape. This meeting created space to be "...able to actually talk in detail about the why of their concerns, and share in detail about actually what the project looked like.... [which]was very productive" (1.2P). Initiative leads then offered to adapt aspects of the physical appearance of fridge, highlight support from local businesses and shared ideas to improve media interactions in the future. This opportunity was seized on by the key business actors involved. The unfolding conversations then created " a [sense] of comradery...like [we] were in that together" 
(1.2P). Through the subsequent co-design process, underlying emotions and actions of the key business actors significantly shifted, from "almost shouting [to]... saying I'm actually quite excited" (1.1P) with further ideas proposed for working together to continue to enhance the site and immediate area. This further helped to shift the experiences of key business owners from resigned acceptance to enthusiasm about the initiative.

The initial showing of empathy combined with acceptance by business owners of the initiative then enhanced interpretation and interconnection, and began a reinforcing regenerative dynamic. This included enhanced shared understanding of concepts, clarified assumptions, more positive emotions, new connections, more aligned identities and emerging solidarity around shared challenges and goals. As this regenerative dynamic unfolded, two additional social aspects began to emerge, further reinforcing regenerative outcomes and processes: alignment to common purpose and values and learning.

The actions of the initiative leads were already guided by an explicit purpose and underlying values, which were "to add and benefit our community" (1.2P) that entailed "[not creating] any negative impact" (1.2P) for any social group. This had already included local businesses, with one lead already having commented that "we want [local businesses] to be our biggest fans [for the initiative to be a success in the future]" (1.2P). This purpose was underpinned by previous experience of initiative leads and their underlying values for achieving "social good [and] care for the planet" (1.2P). As a more beneficial interpretation and interconnection dynamic emerged, the purpose and underlying values could be more clearly expressed. As this occurred, a more widely shared and aligned purpose and values began to take shape. This led to a willingness to work together between more diverse actors, with the result that relationships were further strengthened. One key business owner commented "they were very kind...they didn't have to do that...it was good of them" (1.4B), and as interpretation and interconnection dynamics improved, so did capacity for collective problem solving.

Opportunity for learning was also enhanced. For example, empathy created space for dialogue for initiative leads to gain new insights about the underlying emotions shaping the actions of key business actors. One initiative lead commented "[key business owners had] a lot of time to think and make it into something else in their heads..... I now see they were] so compounded by their fears that they weren't able to hear any of the good stuff" (1.1P). This helped initiative leads see how to adapt future actions to better understand and reduce tensions, with one commenting "we'd approach it differently....we know how well [fridges] have worked elsewhere, but no-one else does" (1.2P).
Learning also emerged for local business owners, such as about the nature of the initiative. One commented how they understood the aim to be to help address "food waste.... rather than [being] a food kitchen, which is a bit different....it's an addition to the area" (2.1B) and another who felt they "see it now, it's a really good idea" (1.4B). It also led to practical learning about improving interactions for sharing information, exploring concerns and developing understanding between actors in the future. One commented, for example, that "I'll probably just ask for more private meetings than a public one" (1.4B). This was emphasised as particularly important when dealing with novel ideas where "there were always going to be crosslines" (1.4B) and involved a key business owners to convey a willingness to help strengthen this sense-making process elsewhere "to encourage other community fridges in other areas, giving other people comfort... because no doubt [small businesses elsewhere] will have the same concerns as us" (1.4B). Overall, the enhanced opportunity to learn as the quality of social relations were enhanced included: learning by leads about how to improve dialogue and interaction in future initiatives and by key business owners about the concepts; intentions and potential local benefits; the need to improve dialogue for future collective problem solving, including tangible ideas about how to do it.

In summary, as qualities of social relationships improved, the project shifted from being dominated by a degenerative dynamic towards being one that was regenerative, where beneficial reinforcing dynamics came to the fore. Importantly this was initiated by the leads showing empathy and their project being founded on core values that sought to achieve unity. The improving quality of social relationships were then driven by the same reinforcing social dynamics of interpretation and interconnection, which began to shift in more beneficial directions as dissonance between different and polarised groups reduced as they began to work together. This included enhanced alignment of purpose and values, as well as enhanced learning.

\section{Discussion}

\section{Inductively derived insights from case study}

The findings highlight four social dynamics were key in shaping how the process to establish the community fridge unfolded. As these different dynamics intersected over time within the process three stages can be distinguished. The first stage involved the dynamics of reinforcing interpretation intersecting with the dynamic of reinforcing interconnections. Initially as uncertainty and existing interconnections between business owners came together doubts were amplified, factions emerged and tensions increased. Through this 


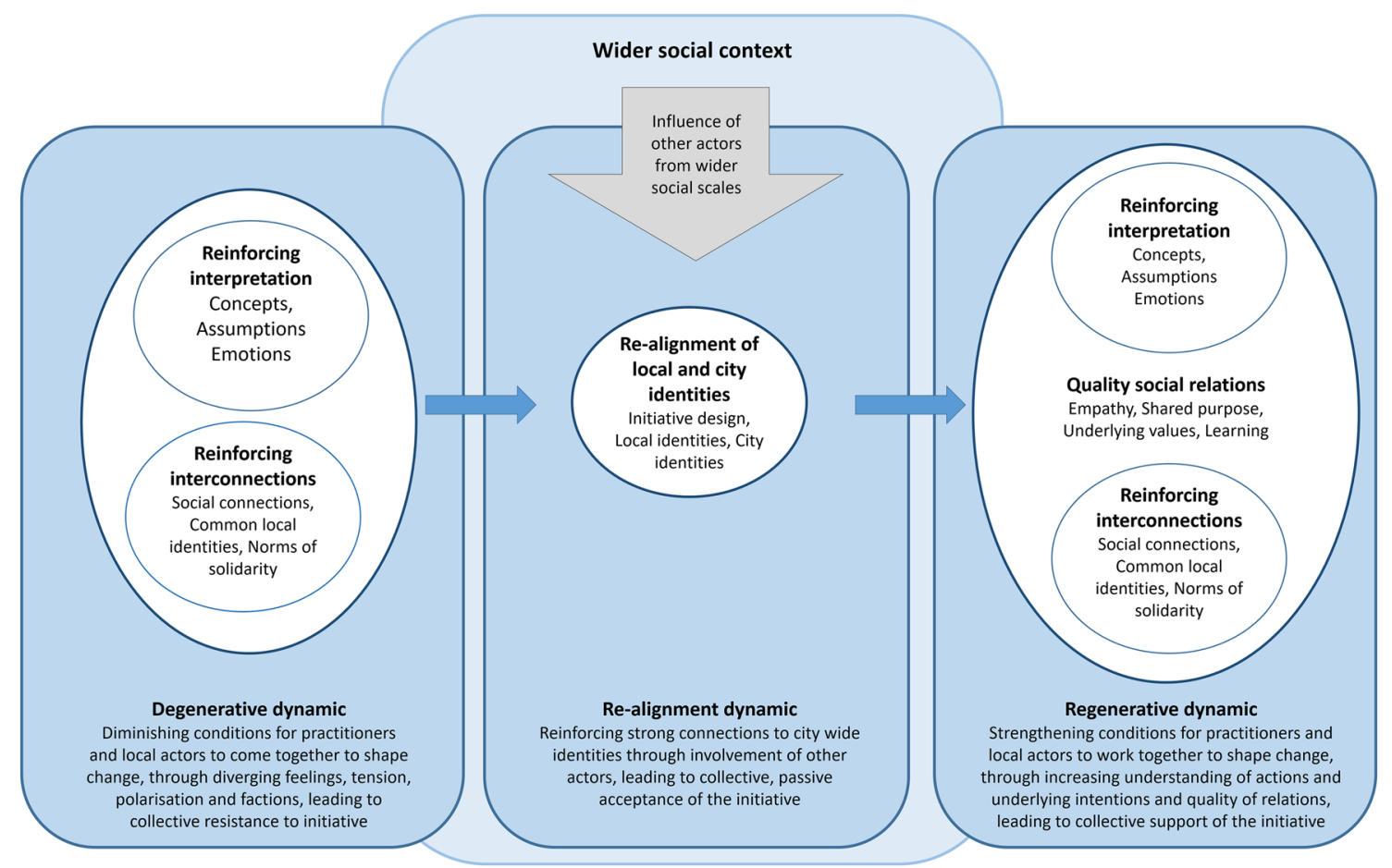

Fig. 3 The key social dynamics that shaped how the process to establish the community fridge unfolded through three stages (degenerative dynamic, re-alignment dynamic and regenerative dynamic)

collective resistance to the initiative unfolded and increased. Together, this created what we consider to be a degenerative dynamic where this combination of processes reinforce each other in ways to increase tension, polarisation, separation, and factions, through which collective local resistance to the initiative continued to gain traction and conditions for actors engaging in the process to come together to shape the change process diminished over time (Fig. 3). Within complex collective change processes, tension between actors with different perspectives and understandings of the multiple dimensions of initiatives is inherent (Collier 2009; Anderson 2013). In this case, such tension unfolded in a relatively short time frame, enabling a close (in depth) exploration of the diverse factors and interconnections involved. This role of heightened tension in surfacing less visible factors within collective change processes is also highlighted as important by Antonacopoulou and Chiva (2007).

The nature of this degenerative dynamic catalysed action (of actors on the periphery) to engage other actors, creating a second stage of the process shaped by a social dynamic of re-alignment between local and city-wide identities. This dynamic surfaced a strong link between the initiative and city identities and through this passive acceptance of the initiative unfolded (Fig. 3). This second stage can therefore be considered as emergent (Holman 2010), which, whilst unforeseen by some local actors, arose in part as a response to what had gone before and to surface connections to wider social identities incorporated into the design of the initiative from the start.

From this, a new set of social dynamics emerged. This began as initiative leads were able to read a change in mood and express the underlying values of inclusion, which together opened up opportunities for sharing and identifying a common purpose. This then helped create a possibility for greater collaboration and greater interaction among different actors that then built quality social relations and greater active support for the initiative. We take this to be a regenerative dynamic, with diverse social factors actively reinforcing each, facilitating learning, supporting shared interpretations and improving interconnections, enhancing the quality of social relations in the process that continually strengthens conditions for collective action between key individuals (Fig. 3). While beyond the scope of this paper, it seems likely that, through continued interactions within this initiative over time, the regenerative dynamics would enable further collaborative work on other initiatives, in ways that would not have been possible prior to the fridge project. Thus, while this social dynamic unfolded in response to understandings about what had gone before, this social dynamic and how it shaped the final stage of the process were guided by embedded social values held by the practitioners leading the initiative.

Overall, this highlights, even when initiatives are relatively small in scale, many different facets are involved in 
shaping how such processes unfold. Whilst the nature of such facets will vary across contexts, how actors more generally, and community practitioners in particular, engage with different facets within initiatives matters, shaping what unfolds and how, and thus how actors perceive and experience change processes over time. More specifically, it highlights that if dynamics of interpretation and interconnections are not well managed a degenerative process can emerge. Equally, and in combination with the right contextual conditions, if purpose, values and identities can be aligned, then the reinforcing nature of interpretation, interconnection, and learning can lead to the development of quality social relations and a (re)generative dynamic, where beneficial outcomes and relationships build conditions for collective action and outcomes to strengthen future collaborative capacities.

\section{Conceptual and practical implications}

Social relationships are considered as key within change initiatives; however as these findings show, they entail more than the presence of social connections between different actors (Bernhard 2018). This study highlights that a key role of social relationships in change initiatives involves shaping how aspects of initiatives are interpreted, actions and interactions unfold over time. Social relationships are predefined social spaces of interaction shaped by diverse normative dimensions, including social identities and relational norms, and which actors then draw on to explore new situations and potential problems. The dynamic interconnections between different social identities and relational norms influence relational spaces within change processes in ways that may help reinforce or challenge assumptions, or enable alternative perspectives to be explored, from which new insights may emerge (e.g. on what is and is not acceptable or desirable). Thus, as different normative factors come to the fore, the way relational spaces contribute also shift, with potential for opening up opportunities to build shared understandings and relationships for the future, strengthening conditions for collectively shaping change going forward.

The role of social relationships in change initiatives is often conceptualised in terms of social capital (e.g. Dale and Newman 2010), yet as a core component of social capital, social relationships themselves are usually often poorly defined. More broadly, simplistic approaches to social capital are not uncommon (Rockenbauch et al. 2019). This is problematic by underplaying the normative dimensions involved (Carmen et al. 2022) and the complex social dynamics shaping the role of social relationships within change initiatives in practice (Rockenbauch and Sakdapolrak 2017), as highlighted in this study. Our study points to the importance of conceptualising social relations in change initiatives as semi-structured, dynamic normative spaces of connection and exploration. This adds nuance to help convey social relationships as qualitatively diverse and in terms of their meaning-making role (Bernhard 2018) and aligns with calls to overcome simplistic approaches to social capital by adopting a socio-spatial perspective to better engage with context, place and space (Naughton 2014). Furthermore, the potential for undesirable outcomes from social capital is widely acknowledged in the literature (Putzel 1997; Portes and Landolt 1996), including how social capital can hamper collective agency (Oteng-Ababio et al. 2015). This more dynamic, normative understanding of relational spaces in change processes also helps to see how different outcomes and their perceived desirability for actors can vary across temporal and spatial scales (e.g. desirable to progress a change initiative, for specific local livelihoods and/ or a local community as a whole). Such nuance is critical for understanding how engagement with social relationships can shape collective outcomes in ways that engage with and help build capacity for complex sustainability challenges.

These findings have three important practical implications for approaching change initiatives and working through social relationships within these complex social processes. First, there is a need for initiatives to carefully guide how issues and change is interpreted. The findings highlight that as unfamiliar circumstances unfold, local actors reach for cues to contribute to a process of interpretation and re-interpretation and these cues shape assumptions and emotions for those involved. There is therefore a need for new initiatives to be understood as a process of narratives-in-the-making, constructed through experience of and between actors in the process. The importance of narratives is increasingly recognised in how challenges such as climate change are approached (Bushell et al. 2017), potentially helping to open up new opportunities for action (Garud et al. 2014) and to shape collective movements (Polletta 1998). As shown in this study, this process of interpretation may unfold in ways that can both diverge from (as part of a degenerative dynamic), or converge around core intentions embedded within initiatives (as part of a regenerative dynamic). Guiding the co-construction of initiative narratives through dialogue is therefore key for limiting the potential for different understandings to amplify tensions between actors, for example by selecting and using appropriate metaphors to help convey core intentions to guide interpretation. Decisions and what emerge are, in part, influenced by interconnections between underlying factors, such as values and knowledge (Gorddard et al. 2016). This study suggests that deliberate engagement in narrative-in-the-making within initiatives could support different actors to more quickly align their thinking and actions (helping to limit the reinforcing nature of factors within a degenerative dynamic), to surface shared values and develop shared understandings that enable opportunities for further action in the future, which 
were critical in bringing about a regenerative dynamic the this case. Crafting narratives within initiatives is therefore also performative as links between actions and meanings are dynamically re-configured, guiding how circumstances unfold (Riedy et al. 2019).

Second, different social identities influence how actors relate to each other and position themselves as they engage in initiatives. Normative factors (e.g. identities, values and beliefs) are increasingly recognised as important dimensions of change processes (Masterson et al. 2017). This includes an emphasis on place-based identities and a need to strengthen connections to place through action (Grenni et al. 2020; Smith et al. 2015). This study shows that although some social identities are likely to be perceived as being at odds with understandings of initiatives as circumstances unfold, the diversity of social identities also creates opportunities to build connections with initiatives as they develop. Local knowledge of shared social identities at the community level and aligning with them in the design of initiatives is thus important. Initially, the limited recognition and divergence away from this connection with wider social identities in the process instigated a re-alignment stage, which reiterated the importance of this connection for other actors within the social context. Collective change initiatives are however complex social processes (Fazey et al. 2021), within which the perceived importance of different facets (of shared identities, other aspects of communities and/or initiatives) may shift, as occurred in this case within the re-alignment stage. Engaging with change initiatives as continual processes of learning (for all) is therefore also important. Whilst learning is widely recognised as critical for shaping how change processes unfold (Orleans Reed et al. 2013), this study shows how a learning approach could further strengthen understanding about connections with social identities and thus help actors to better view initiatives as contributing to (not weaken) a shared place-based identity. For this to emerge in practice, however, engagement with diverse actors across social scales is also needed to help define and refine understandings of identities to contextualise initiatives as they develop and help limit the reinforcing nature of factors involved in shaping a degenerative dynamic.

Third, an inclusive social purpose and underlying values are critical within collective sustainability change processes for navigating through perceived value-based contradictions between actors. Whilst tensions may be inevitable, this study also shows that tensions also need to be understood as opportunities to express and therefore surface values for guiding future outcomes. Thinking in this way helps move away from 'us versus them' framings to those focused on 'we'. Building 'we' intentions is important for enhancing collective agency and for finding ways to reconfigure social boundaries to help develop capacity for more transformative kinds of change (O'Brien et al. 2019; Tuomela 2005). In the case of the community fridge initiative, this was made possible because of the way the core initiative leads held strong underlying values of a desire for collective benefits and empathic responses to those who initially opposed the project. Future projects thus need to actively build in the surfacing of tensions and be guided by deeply embedded core values that help drive unity, working with and strengthening shared identities and supporting opportunities for shared understandings about initiatives to develop. Thus, holding and expressing social values through action is important to shape future orientated learning, capacity and action for shaping regenerative dynamics within change processes.

\section{Implications for future research}

The study also has implications for research to advance more dynamic understandings of the role of social relationships and complex sustainability initiatives. First, while aspects of power, including the power of different ideas (e.g. the uncontested idea of climate action) and the shifting capacity of actors to mobilise others, were drawn on in the analysis, the lens of social power was not explicitly used. Social power, including the power to dominate different spaces, is a highly complex issue and well known to be critical in shaping initiatives (Avelino 2017; Mudliar and Koontz 2020). A power lens could help explore in more depth how interconnections involving multiple normative dimensions across social scales and through time intersect with social relationships to influence social dynamics and transitions between stages of change processes as defined and explored in this paper. Second, whilst connections to the wider city context was important in helping to establish the fridge, exploring the role of wider governance contexts was beyond the scope of this study. Such wider formal contexts have received considerable attention in the literature (Westley et al. 2013; Hölscher et al. 2019), and incorporating this into a social dynamic approach could help advance understanding about how issues of governance may also influence the social dynamics within initiatives and, importantly, how to better enable the development of regenerative social dynamics for building collective capacity for the longer term.

\section{Conclusions}

This study examined the social dynamics in establishing a community-based climate action initiative and included the role of different aspects of social relations within initiatives. The findings show that social dynamics relating to interpretations and interconnections (or social relationships) can intersect in ways that shape what we suggest to be a degenerative dynamic. They can also be guided through alignment with wider social identities and expressions of inclusive 
social values to create what we refer to as a regenerative dynamic where reinforcing social dynamics build conditions for different actors to continue to work together to shape change over longer time frames. This involves enhanced learning, relationships and identifying a shared purpose.

Overall, we highlight that future community-based change initiatives need to be guided by explicit approaches that work with social relationships but where these relationships are conceptualised as dynamic normative spaces of interaction and exploration. Approaching relationships in this way can help the design and implementation of initiatives to create beneficially reinforcing and regenerative kinds of dynamics, where advances in one facet support others and increase collective capacities for change. Understanding and developing such regenerative potential will be critical for the development of capacities for working with major challenges such as climate change that are rapidly affecting human societies across the world.

Acknowledgements UK Economic and Social Research Council funding and Write up PhD funding from Konrad Lornenz Institute (Austria) were obtained. Gate Church Carbon Saving project is acknowledged for hosting and supporting this research.

Funding UK Economic and social research council, ES/J500136/1, Esther Carmen.

\section{Declarations}

Conflict of interest The authors declare that they have no conflict of interest.

Open Access This article is licensed under a Creative Commons Attribution 4.0 International License, which permits use, sharing, adaptation, distribution and reproduction in any medium or format, as long as you give appropriate credit to the original author(s) and the source, provide a link to the Creative Commons licence, and indicate if changes were made. The images or other third party material in this article are included in the article's Creative Commons licence, unless indicated otherwise in a credit line to the material. If material is not included in the article's Creative Commons licence and your intended use is not permitted by statutory regulation or exceeds the permitted use, you will need to obtain permission directly from the copyright holder. To view a copy of this licence, visit http://creativecommons.org/licenses/by/4.0/.

\section{References}

Anderson C (2013) Energy Policy, 58, Pp.97-108. 2013. The networked minority: how a small group prevailed in a local windfarm conflict. Energy Policy 58:97-108

Andrachuk M, Armitage D (2015) Understanding social-ecological change and transformation through community perceptions of system identity. Ecol Society. https://doi.org/10.5751/ ES-07759-200426

Ansell CK (2011) Pragmatist democracy: evolutionary learning as public philosophy. Oxford University Press, New York
Antonacopoulou E, Chiva R (2007) The social complexity of organizational learning: the dynamics of learning and organizing. Manag Learn 38:277-295

Avelino F (2017) Power in sustainability transitions: Analyising power and (dis)empowerment in transformative change towards sustainabaility. Environ Policy Gov 27:505-520

Becker SL, Franke F, Gläsel A (2018) Regime pressures and organizational forms of community-based sustainability initiatives. Environ Innov Soc Trans 29:5-16

Bernhard S (2018) Analyzing meaning-making in network ties - a qualitative approach. Int J Qual Methods 17:1-11

Blaikie N (2010) Designing social research. Polity Press, Cambridge

Bodin Ö, Crona BI (2009) The role of social networks in natural resource governance: what relational patterns make a difference? Glob Environ Chang 19:366-374

Bohle HG, Downing TE, Watts MJ (1994) Climate change and social vulnerability: toward a sociology and geography of food insecurity. Glob Environ Chang 4:37-48

Boulton JG, Allen PM, Bowman C (2015) Embracing complexity: strategic perspectives for an age of turbulence. Oxford University Press, Oxford

Bushell S, Buisson GS, Workman M, Colley T (2017) Strategic narratives in climate change: towards a unifying narrative to address the action gap on climate change. Energy Res Soc Sci 28:39-49

Byrne D, Callaghan G (2014) Complexity theory and the social sciences: the state of the art. Oxford (UK) and New York (USA), Routledge

Caniglia G, Luederitz C, Von Wirth T, Fazey I, Martin-López B, Hondrila K, König A, Von Wehrden H et al (2020) A pluralistic and integrated approach to action-oriented knowledge for sustainability. Nat Sustain. https://doi.org/10.1038/s41893-020-00616-Z

Carmen E, Fazey I, Ross H, Bedinger M, Smith FM, Prager K, Mcclymont K, Morrison D (2022) Building community resilience in a context of climate change: the role of social capital. Ambio (accepted)

Chow WS, Chan LS (2008) Social network, social trust and shared goals in organizational knowledge sharing. Info Manag 45:458-465

Collier M, Scott M (2009) Conflicting rationalities, knowledge and values in scarred landscapes. J Rural Stud 25:267-277

Crang M, Cook I (2007) Doing ethnographies. SAGE publications

Dale A, Newman L (2010) Social capital: a necessary and sufficient condition for sustainable community development? Commun Develop J 45(1):5-21

Dale A, Onyx J (2010) A dynamic balance: social capital and sustainable community development. UBC Press

De Vos A, Biggs R, Preiser R (2019) Methods for understanding socialecological systems: a review of place-based studies. Ecol Soc 24:16

Demski C, Butler C, Parkhill KA, Spence A, Pidgeon NF (2015) Public values for energy system change. Glob Environ Chang 34:59-69

Eberly MB, Holley EC, Johnson MD, Mitchell TR (2011) Beyond internal and external: a dyadic theory of relational attributions. Acad Manag Rev 36:731-753

Emery ME, Bregendahl C (2014) Relationship building: the art, craft, and context for mobilizing the social capital necessary for systems change. Community Dev 45:279-292

Etzion D, Gehman J, Ferraro F, Avidan M (2017) Unleashing sustainability transformations through robust action. J Clean Prod 140:167-178

Everard M, Reed MS, Kenter JO (2016) The ripple effect: Institutionalising pro-environmental values to shift societal norms and behaviours. Ecosyst Services 21:230-240

Fahrenbach F, Kragulj F (2019) The ever-changing personality: revisiting the concept of triple-loop learning. The Learn Organ 27(6):499-512 
Farjoun M, Ansell C, Boin A (2015) PERSPECTIVE-Pragmatism in organization studies: meeting the challenges of a dynamic and complex world. Organ Sci 26:1787-1804

Fazey I, Carmen E, Chapin FS, Ross H, Rao-Williams J, Lyon C, Connon ILC, Searle BA et al (2018a) Community resilience for a $1.5^{\circ}$ C world. Curr Opin Environ Sustain 31:30-40

Fazey I, Moug P, Allen S, Beckmann K, Blackwood D, Bonaventura M, Burnett K, Danson M et al (2018b) Transformation in a changing climate: a research agenda. Climate Dev 10:197-217

Fazey I, Schäpke N, Caniglia G, Patterson J, Hultman J, Van Mierlo B, Säwe F, Wiek A et al (2018c) Ten essentials for action-oriented and second order energy transitions, transformations and climate change research. Energy Res Soc Sci 40:54-70

Fazey I, Carmen E, Ross H, Rao-Williams J, Hodgson A, Searle B, Al Waer H, Kenter J et al (2021) Social dynamics of community resilience building in the face of climate change: the case of three Scottish communities. Sustain Sci 16(5):1731-1747

Fazey I, Wise RM, Lyon C, Câmpeanu C, Moug P, Davie TE (2016) Past and future adaptation pathways. Climate Dev 8:26-44

Fehr E, Fischbacher U (2004) Social norms and human cooperation. Trends Cogn Sci 8:185-190

Fresque-Baxter JA, Armitage D (2012) Place identity and climate change adaptation: a synthesis and framework for understanding. Wiley Interdiscip Rev: Clim Change 3:251-266

Garnett T (2014) Three perspectives on sustainable food security: efficiency, demand restraint, food system transformation. What role for life cycle assessment? J Clean Prod 73:10-18

Garud R, Gehman J, Giuliani AP (2014) Contextualizing entrepreneurial innovation: a narrative perspective. Res Policy 43:1177-1188

Gomm R (2008) Observing naturall ocurring events. In: Gomm R (ed) Social research methodology: a critical introduction. Basingstoke, UK, Palgrave MacMillian

Gorddard R, Colloff MJ, Wise RM, Ware D, Dunlop M (2016) Values, rules and knowledge: adaptation as change in the decision context. Environ Sci Policy 57:60-69

Granderson AA (2014) Making sense of climate change risks and responses at the community level: a cultural-political lens. Clim Risk Manag 3:55-64

Grenni S, Soini K, Horlings LG (2020) The inner dimension of sustainability transformation: how sense of place and values can support sustainable place-shaping. Sustain Sci 15:411-422

Hahn T, Nykvist B (2017) Are adaptations self organsized, autonomous and harmonious? Assessing the social-ecologica; resilience literature. Ecol Soc 22:12

Hausman AJ, Becker J, Brawer R (2005) Identifying value indicators and social capital in community health partnerships. J Commun Psychol 33(6):691-703

Holman P (2010) What is emergence? In: Holman P (ed) Engaging emergence: turning upheaval into opportunity. Berrett-Koehler Publishers, San Francisco

Hölscher K, Frantzeskaki N, Loorbach D (2019) Steering transformations under climate change: capacities for transformative climate governance and the case of Rotterdam, the Netherlands. Reg Environ Change 19:791-805

Horlings LG (2015) The inner dimension of sustainability: personal and cultural values. Curr Opin Environ Sustain 14:163-169

Igalla M, Edelenbos J, Van Meerkerk I (2019) Citizens in action, what do they accomplish? A systematic literature review of citizen initiatives, their main characteristics, outcomes, and factors. Int J Voluntary Nonprofit Organizations 30:1176-1194

Ison R (2018) Governing the human-environment relationship: systemic practice. Curr Opin Environ Sustain 33:114-123

Katrini E (2018) Sharing culture: on definitions, values, and emergence. The Sociol Rev 66:425-446
Kilpatrick S, Falk I (2003) Learning in agriculture: building social capital in island communities. Local Environ. https://doi.org/10. 1080/762742066

Köhler J, Geels FW, Kern F, Markard J, Onsongo E, Wieczorek A, Alkemade F, Avelino F et al (2019) An agenda for sustainability transitions research: state of the art and future directions. Environ Innov Soc Trans 31:1-32

Laakso S, Berg A, Annala M (2017) Dynamics of experimental governance: a meta-study of functions and uses of climate governance experiments. J Clean Prod 169:8-16

Lang DJ, Wiek A, Bergmann M, Stauffaher M, Martens P, Moll P, Swilling M, Thomas CJ (2012) Transdisciplinary research in sustainability science: practices, principles, and challenges. Sustain Sci 7:1-19

Laycock KE, Mitchell CL (2019) Social capital and incremental transformative change: responding to climate change experts in Metro Manila. Clim Change 15:47-66

Macgillivray BH (2018) Beyond social capital: the norms, belief systems, and agency embedded in social networks shape resilience to climatic and geophysical hazards. Environ Sci Policy 89:116-125

Macintyre T, Lotz-Sisitka H, Wals A, Vogel C, Tassone V (2018) Towards transformative social learning on the path to 1.5 degrees. Curr Opin Environ Sustain 31:80-87

Madsen W, O'mullan C (2016) Perceptions of community resilience after natural disaster in a rural australian town. J Commun Psychol 44:277-292

Mancilla García M, Hertz T, Schlüter M, Preiser R, Woermann M (2020) Adopting process-relational perspectives to tackle the challenges of social-ecological systems research. Ecol Society. https://doi.org/10.5751/ES-11425-250129

Masterson VA, Stedman RC, Enqvist J, Tengö M, Giusti M, Wahl D, Svedin U (2017) The contribution of sense of place to socialecological systems research: a review and research agenda. Ecol Soc 22:49

Mcfarlane C (2011) The city as a machine for learning. Trans Inst Br Geogr 36:360-376

Miah JH, Griffiths A, Mcneill R, Poonaji I, Martin R, Morse S, Yang A, Sadhukhan J (2015) A small-scale transdisciplinary process to maximising the energy efficiency of food factories: insights and recommendations from the development of a novel heat integration framework. Sustain Sci 10:621-637

Moore M, Westley F (2011) Surmountble chasms: networks and social innovation for resilient systems. Ecol Soc 16:5

Morrow O (2019) Community self-organizing and the urban food commons in Berlin and New York. Sustainability 11:3641

Mudliar P, Koontz TM (2020) Locating power in Ostrom's design principles: watershed management in India and the United States. Soc Nat Resour 34(5):639-658

Naughton L (2014) Geographical narratuves of social capital: telling different stories about the socio-economy with context, space, place, power and agency. Prog Hum Geogr 38:3-21

O'brien K, Sygna L (2013) Responding to climate change: the three spheres of transformation. Proceedings of Transformation in a Changing Climate, 19-21

O'brien K, Hochachka G, Gram-Hanssen I (2019) Creating a culture for transformation. In: Feola G, Geoghegan H, Arnall A (eds) Climate and culture: multidisciplinary perspectives of knowing, being and doing in a climate change world. Cambridge Unviversity Press, Cambridge

Orleans Reed S, Friend R, Toan VC, Thinphanga P, Sutarto R, Singh D (2013) "Shared learning" for building urban climate resilienceexperiences from Asian cities. Environ Urban 25:393-412

Oteng-Ababio M, Sarfo KO, Owusu-Sekyere E (2015) Exploring the realities of resilience: case study of Kantamanto Market fire in Accra, Ghana. Int J Disast Risk Reduction 12:311-318 
Pelenc J, Bazile D, Ceruti C (2015) Collective capability and collective agency for sustainability: a case study. Ecol Econ 118:226-239

Pelling M, O'brien K, Matyas D (2015) Adaptation and transformation. Clim Change 133:113-127

Phillips M (2016) Assets and affect in the study of social capital in rural communities. Sociol Rural 56(2):220-247

Polletta F (1998) Contending stories: narrative in social movements. Qual Sociol 21:419-446

Portes A, Landolt P (1996) The downside of social capital. Am Prospect 26:18-21

Preiser R, Biggs R, De Vos A, Folke C (2018) Social-ecologcical systems as complex adptative systems: organsizing principles for advancing research methods and approaches. Ecol Soc 23:46

Putzel J (1997) Policy arena: accounting for the 'dark side'of social capital: reading Robert Putnam on democracy. J Int Dev 9:939-949

Quinn Patton M (2002) Particularly appropriate qualitative applications. In: Quinn Patton M (ed) Qualitative research and evaluation methods. Sage Publications, Thousand Oaks

Reed MS, Evely AC, Cundill G, Fazey I, Glass J, Laing A, Newig J, Parrish B et al (2010) What is social learning? Ecol Society 15(4):r1

Riedy C, Kent J, Thompson N (2019) Meaning work: Reworking institutional meanings for environmental governance. J Environ Planning Manage 62:151-171

Rockenbauch T, Sakdapolrak P (2017) Social networks and the resilience of rural communities in the Global South: a critical review and conceptual reflections. Ecol Soc 22:10

Rockenbauch T, Sakdapolrak P, Sterly H (2019) Beyond the localExploring the socio-spatial patterns of translocal network capital and its role in household resilience in Northeast Thailand. Geoforum 107:154-167

Rubin HJ, Ruben IS (2005) Structuring the interview. In: Rubin HJ, Ruben IS (eds) Qualitative interviewing the art of hearing data. Sage Publications, Thousand Oakes

Ryan K (2016) Incorporating emotional geography into climate change research: a case study in Londonderry, Vermont, USA. Emotions Space Society 19:5-12

Saldana J (2016) The coding manual for qualitative researchers. Sage

Samouel P (2007) Does time impact relational norms in bilateral exchange? The small business case. J Small Bus Enterprise Develop. https://doi.org/10.1108/14626000710727944

Schlüter M, Haider LJ, Lade SJ, Lindkvist E, Martin R, Orach K, Wijermans N, Folke C (2019) Capturing emergent phenomena in social-ecological systems: an analytical framework. Ecol Society. https://doi.org/10.5751/ES-11012-240311
Scoones I, Stirling A, Abrol D, Atela J, Charli-Joseph L, Eakin H, Ely A, Olsson P et al (2020) Transformations to sustainability: combining structural, systemic and enabling approaches. Curr Opin Environ Sustain 42:65-75

Scottish Government (2020) Scottish Index of multiple deprivation. Scottish Government

Silverman D (2006) Ethnography and observation. In: Silverman D (ed) Interpreting qualitative data. Sage Publications, London

Smith JW, Anderson DH, Moore R (2012) Social capital, place meanings, and perceived resilience to climate change. Rural Sociol 77:380-407

Smith LG, Thomas EF, Mcgarty C (2015) "We must be the change we want to see in the world": integrating norms and identities through social interaction. Poltical Psychol 36:543-557

Spring CA, Biddulph R (2020) Capturing waste or capturing innovation? Comparing self-organising potentials of surplus food redistribution initiatives to prevent food waste. Sustainability 12:4252

Stedman RC (2016) Subjectivity and social-ecological systems: a rigidity trap (and sense of place as a way out). Sustain Sci 11:891-901

Strambach S, Pflitsch G (2018) Micro-dynamics in regional transition paths to sustainability-Insights from the Augsburg region. Appl Geogr 90:296-307

Tuomela R (2005) We intentions revisited. Philos Stud 125:327-369

Van Kerkhoff L (2014) Developing integrative research for sustainability science through a complexity principles-based approach. Sustain Sci 9:143-155

Vermeulen SJ, Campbell BM, Ingram JS (2012) Climate change and food systems. Ann Rev Environ Resour 37(1):195-222

Voss JP, Newig J, Kastens B, Monstadt J, Nölting B (2007) Steering for sustainable development: a typology of problems and strategies with respect to ambivalence, uncertainty and distributed power. J Environ Planning Policy Manage 9:193-212

Watson N (2017) Dundee: a short history. Black and White Publishing Ltd, Edinburgh, Scotland

Westley FR, Tjornbo O, Schultz L, Olsson P, Folke C, Crona B, Bodin Ö (2013) A theory of transformative agency in linked social-ecological systems. Ecol Society. https://doi.org/10.5751/ ES-05072-180327

Publisher's Note Springer Nature remains neutral with regard to jurisdictional claims in published maps and institutional affiliations. 